\title{
Analysis on the Important Application of Geophysical Exploration Technology
}

\author{
Dan $\mathrm{Yu}$ \\ Liaohe oilfield exploration and Development Research Institute, Panjin, Liaoning 124000 China
}

\begin{abstract}
Geophysical prospecting technology is widely used in current geological exploration, metal exploration, oil and gas resources exploration, etc. This technology has many advantages such as low cost, high efficiency and good accuracy of survey results, and plays an important role in many industries. At present, the level of geophysical prospecting technology in China is constantly improving, and its application effect is also constantly improving, so it is necessary to clarify the key application points of this technology. Therefore, this paper will conduct in-depth research and Analysis on the important applications of geophysical exploration technology, elaborate the basic concepts and specific applications of geophysical exploration technology, and put forward some reasonable opinions and measures, in order to further improve the application level of this technology.
\end{abstract}

Keywords: Geophysical survey technology; Basic concepts; Specific application; geological prospecting; Optimization measures

\section{Introduction}

Geophysical exploration technology is widely used, which can accurately obtain the specific information of the explored area, so as to determine the actual situation of the earth structure. It has good application effect in the fields of construction engineering and metal exploration, and can provide scientific information and data support for subsequent development and construction. Geophysical exploration technology is a general term of technology, which includes the application of many specific technologies, and different technologies have corresponding principles and characteristics. In order to further promote the application level of geophysical exploration technology, this paper analyzes its specific application in many fields.

\section{Brief introduction to geophysical exploration technology}

Geophysical exploration technology is a professional category of geology. It takes the content of physics as the technical basis, uses the measurement and observation of the change and distribution of physical field, completes the exploration of the earth's constituent elements, various material structures existing in space and their evolution process, and can analyze the change law to obtain the geological structure, geological conditions and At the same time, it plays an important role in natural disaster monitoring, prediction and response. Because there are some differences in density, elasticity, conductivity, radioactivity, thermal conductivity and magnetism among the different rock media that make up the crust, and the differences will cause local changes in geophysical fields, by controlling the distribution and changes of these differences, the goal of geophysical prospecting can be achieved. Compared with other geophysical exploration technologies, geophysical exploration technology has many advantages, such as portable equipment, low cost, high investigation efficiency and wide working space, and is usually used in combination with drilling technology [1].

Geophysical exploration technology is usually based on the physical properties of rock strata, such as rock permeability, rock density, rock conductivity, rock elasticity, rock thermal conductivity and rock radioactivity. Common exploration methods include gravity exploration method, magnetic exploration method, electrical exploration method, seismic exploration method, geothermal exploration method and nuclear exploration method. According to the spatial location and area where geophysical exploration technology is applied, it can be divided into ground geophysical exploration method, aerial geophysical exploration method, marine geophysical exploration method and drilling geophysical exploration method, etc. According to different exploration objects, it can be divided into metal geophysical exploration method, petroleum geophysical exploration method, coal geophysical exploration method, hydrogeophysical exploration method and engineering geological geophysical exploration method. 


\section{Analysis of specific methods of geophysical exploration technology}

\section{Analysis of gravity exploration method}

Gravity exploration is the most common technical form in geophysical exploration technology. Through precise measuring equipment, the geological strata and the gravity change and density of existing ores are explored and measured, so that the basic situation in the exploration area can be obtained. It has good application effect in the exploration of mineral resources, and can divide faults, magma and rock mass, which is an important basis for mineral prediction [2]. Before the application of gravity exploration method, the density data of rock must be clear before the specific situation can be identified. The following table shows the density values of several common rocks when the method is applied.

Table 1. Density values of common rocks

\begin{tabular}{ccc}
\hline Serial number & Name & Density $(\mathrm{g} / \mathrm{cm} 3)$ \\
\hline 1 & Basalt & $2.6-3.3$ \\
2 & Granite & $2.4-3.1$ \\
3 & Quartzite & $2.6-2.9$ \\
4 & Gneiss & $2.4-2.9$ \\
5 & Mica schist & $2.5-3.0$ \\
\hline
\end{tabular}

\subsection{Magnetic prospecting analysis}

Magnetic exploration method is a technical way to analyze the changes of different magnetic fields by using magnetic equipment and taking the magnetic differences existing in natural ores or rock masses as exploration technology. It has a good application effect in geological problems and mineral resources exploration. The magnetic survey method requires simple operating equipment, small size and high work efficiency, and can ensure the accuracy of survey results, making outstanding contributions in the fields of geological survey and resource exploration in China.

\subsection{Analysis of seismic survey method}

The application of seismic survey method is mainly to detect the medium density elastic wave group in different geological strata, survey the signals and radio waves in the strata through equipment and instruments, and obtain the detailed information of the strata by manually activating the earthquake. It has good results in the fields of coal resources exploration, oil and gas resources exploration and so on. According to the practical application of seismic survey method, taking its application in coal resources exploration as an example, the three-dimensional seismic model built by highresolution imaging technology can intuitively show threedimensional images of geological conditions, thus providing a basis for subsequent exploration work.

\subsection{Analysis of electrical survey method}

The electrical prospecting method is a geophysical prospecting technique with good application effect in recent years, which mainly uses the ground electrical method, aviation electrical method and direct current method to realize the exploration of geological strata. In the process of application, DC method has the highest accuracy, so it has a good application effect in hydrological survey. However, this method has higher requirements for topographic environment, so the survey environment must be treated accordingly before application. In addition, the electrical survey method also includes transient electromagnetic method, which can complete the underground electromagnetic transmission without connecting the return line to form electromagnetic pulse, and then combined with corresponding instruments to obtain various information of geological layers. The following table shows the classification and application of electrical prospecting methods.

Table 2. Classification and application of electrical prospecting method

\begin{tabular}{|c|c|c|c|}
\hline Category & $\begin{array}{c}\text { The nature } \\
\text { of field }\end{array}$ & Method name & Application \\
\hline \multirow{3}{*}{$\begin{array}{l}\text { Direct } \\
\text { current } \\
\text { method }\end{array}$} & \multirow{4}{*}{$\begin{array}{l}\text { Natural } \\
\text { field }\end{array}$} & $\begin{array}{l}\text { Natural electric } \\
\text { field method }\end{array}$ & $\begin{array}{l}\text { Looking for } \\
\text { technical sulfide } \\
\text { deposits and } \\
\text { stratigraphic } \\
\text { mapping of } \\
\text { yellow titanium } \\
\text { mineralization }\end{array}$ \\
\hline & & $\begin{array}{l}\text { Induced } \\
\text { polarization } \\
\text { method }\end{array}$ & $\begin{array}{l}\text { Looking for gold } \\
\text { sulfide deposits, } \\
\text { groundwater } \\
\text { exploration and } \\
\text { oil exploration }\end{array}$ \\
\hline & & Charging method & $\begin{array}{l}\text { Foundation } \\
\text { engineering } \\
\text { exploration and } \\
\text { groundwater } \\
\text { exploration }\end{array}$ \\
\hline \multirow[t]{2}{*}{$\begin{array}{l}\text { AC } \\
\text { electric } \\
\text { method }\end{array}$} & & Resistivity method & $\begin{array}{l}\text { Explore the } \\
\text { Karst } \\
\text { Development } \\
\text { Zone, determine } \\
\text { the fluctuation of } \\
\text { bedrock and } \\
\text { determine the } \\
\text { thickness of } \\
\text { weathered layer }\end{array}$ \\
\hline & $\begin{array}{l}\text { Artificial } \\
\text { field }\end{array}$ & $\begin{array}{c}\text { Frequency } \\
\text { electromagnetic } \\
\text { sounding }\end{array}$ & $\begin{array}{c}\text { Large depth } \\
\text { geological } \\
\text { survey }\end{array}$ \\
\hline
\end{tabular}

\section{Specific application analysis of geophysical prospecting technology in different fields}

Geophysical survey technology has been applied in many fields at present. According to different application objects, different geophysical survey technologies are adopted, and the comprehensive survey results are remarkable, which can effectively guarantee the accuracy of survey results. The following are the specific applications of geophysical survey technology in different fields. 


\subsection{Application of in deep metal mineral resources exploration}

The deep part belongs to the second depth space. In the depth range of $500-2000 \mathrm{~m}$, it is difficult to investigate because of its deep burial depth. Therefore, it is necessary to use corresponding geophysical exploration technology to help the investigators determine the thickness of sedimentary cover structure and weathered layer, and establish deep geophysical inversion model, so as to determine the deep structural environment of metal mining area, At the same time, the deep lithology mapping can be carried out to determine the ore bearing horizon. According to the formation and distribution of the technical mining area, there is a certain relationship between granite body and basic ultrabasic intrusive rock mass. Therefore, geophysical exploration can be used to map the deep lithology in the metal mining area to help the investigators determine the abnormal field distribution and shape of rock mass with different physical attributes. Taking a deep metal mineral resources development project as an example, in the course of investigation in this project, through the technical means of controlled-source audio magnetotelluric emission and based on audio gross electromagnetic method, the working principle of controlled-source audio magnetotelluric method is to introduce harmonic current in a certain audio range to the deep underground, observe the frequency value of the audio, and compare the frequency changes, and finally complete the exploration of deep mineral resources [3].

For some deep concealed ore bodies with obvious physical differences from the surrounding rock, the prospecting work can be carried out directly through aviation and ground geophysical exploration methods, which can realize high-precision geophysical exploration. For example, the aeromagnetic method and electromagnetic survey method of large-scale helicopter carried out by the aerospace remote control center of the Ministry of land and resources in Daye iron mine area. According to the detailed interpretation results, more than 5 layers of iron ore bodies were found in the depth of 720 770 meters, and the accumulated thickness of iron ore bodies exceeded 14 meters. Magnetite, pyrrhotite and chalcopyrite were among the found ores.

\subsection{Application analysis of in nonferrous metal resources exploration}

Generally, nonferrous metals are deeply buried in areas with deep underground depth, so corresponding exploration methods must be adopted to find nonferrous metal minerals. As an important natural resource, nonferrous metals have an important impact on China's industrial production and other aspects. In recent years, the development of China's nonferrous metal exploration industry has been promoted by geophysical exploration technology to a certain extent. The basic principle of geophysical exploration is to identify the physical characteristics of rock strata and lithology in the crust. According to the identification results, it can be clear whether there are non-ferrous metal resources in this area. It is a simple and effective exploration method with fast exploration efficiency and low exploration cost. It is the most basic method in non-ferrous metal exploration. Geophysical exploration technology applied in nonferrous metal exploration is extremely important for the development of China's resource exploration industry. Having more advanced exploration methods means that it can improve the exploration efficiency of nonferrous metal resources and find out more nonferrous metals and related mineral resources distributed in China, which is of great significance for the implementation of China's resource strategy and ensuring national security [4].

\subsection{Application analysis in engineering geological exploration}

Before the development of road engineering, in order to clarify the geological conditions of the construction area, scientific methods must be used to obtain geological information. The application of geophysical exploration technology has good results and can help the construction unit obtain sufficient and accurate geological information. Taking a road construction project in Q city as an example, the road construction needs to build a tunnel. In order to ensure the safety of tunnel construction, after full demonstration by the designers, it is decided to adopt the micro motion survey technology in geophysical survey technology. Micro-motion detection technology makes use of the basic principle that there are weak fluctuations on the earth's surface. The weak fluctuations on the earth's surface come from the basic activities of nature and human beings. These weak fluctuations will spread outward in the form of vibration and contain a certain amount of energy, which mainly propagates in the form of surface waves. By surveying the energy surface waves, the corresponding information in geological structures can be obtained. The following figure shows the equipment structure and operation schematic diagram of micro-motion detection technology.

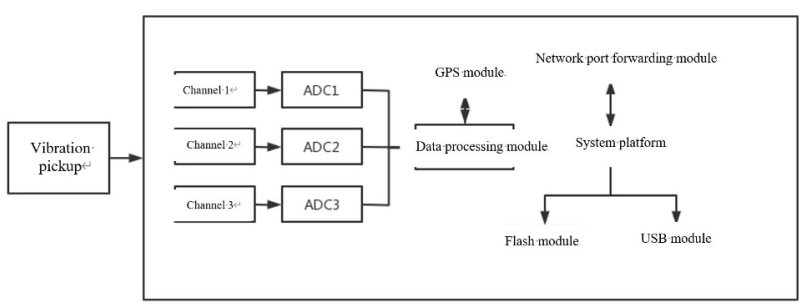

Figure 1. Structure and operation principle of micro motion detection technology equipment

In this project, the basic application process of micro motion geophysical survey technology is: survey station $\rightarrow$ micro motion observation waveform recording $\rightarrow$ Rayleigh wave phase velocity dispersion curve $\rightarrow$ surface wave phase velocity contour map. The main function of the observation station is to collect the signal of micro motion wave, and apply the set algorithm to extract the detected signal from multiple survey stations and record it, then draw it into the Rayleigh wave velocity phase velocity dispersion curve by a specific algorithm, and then draw the contour map directly. According to the contour map, the change of address structure in the detected area can be truly reflected, And all kinds of information in the 
address structure, the results are more accurate. In this tunnel project, two survey lines are set up along the northsouth line of the tunnel, with 70 observation points of the north line survey array and 80 observation points of the south line survey array, thus obtaining the specific geological structure information of the proposed tunnel area, which mainly includes: (1) The fretting wave propagation speed in the tunnel body is relatively slow on both sides near the entrance and exit of the tunnel, and it can be judged from the drilling data that the tunnel near the entrance has passed through silty clay, residual clay and clay. (2) According to the application of combined drilling technology, it can be explained that the middle part of the tunnel mainly passes through the base rock, but there is a certain gap in the velocity of the bottom rock. The relatively complete rock is in the area with high velocity and the relatively broken rock is in the area with low velocity. The change result of surface wave velocity can explain that the continuity of geological structure in the tunnel is poor, It shows that the tunnel body is affected by the nearby fault structure.

\section{Conclusions}

In this paper, the basic concepts of geophysical survey technology are described in detail, and its various application methods are analyzed. Finally, the specific applications of geophysical survey technology in deep metal survey, nonferrous metal survey and geological survey of road engineering are analyzed, hoping to play a certain reference and help role for the development of related fields and industries, and at the same time promote the continuous improvement of geophysical survey technology level.

\section{References}

1. Luo Ji, Tang Wenqian. Analysis on the important application of geophysical exploration technology[J]. China Chemical Industry Trade, 2019, 11(015):85-85.

2. Tong Zhikui. Application analysis of geophysical exploration technology in oil and gas exploration and development[J]. 2021(2015-23):173-173.

3. Long Zhiyuan. Geophysical prospecting technology methods and application research analysis[J]. Electronic Components and Information Technology, 2020, 39(09):118-119.

4. Ruan Jue. Application analysis of integrated geophysical exploration technology in geothermal exploration[J]. Encyclopedia Forum Electronic Journal, 2019, 000(017):784-784.

5. Yu Zhitong, Tian Jian, Xin Zhixiang. Research on the development status and practical application of geophysical exploration technology[J]. World Nonferrous Metals, 2019, 53(002):0058-0058 